\title{
Morphologic and morphometric investigation of plexus brachialis in rat
}

\author{
Davut Özbağ ${ }^{1}$, Yakup Gümüşalan ${ }^{1}$, Sevgi Bakarişs ${ }^{2}$, Harun Çıralık², Mehmet Şenoğlu ${ }^{3}$ Ali Murat Kalender ${ }^{4}$ \\ ${ }^{1}$ Department of Anatomy, Faculty of Medicine, Kahramanmaraşsiitçii İmam University, Kahramanmaraş, Turkey \\ ${ }^{2}$ Department of Pathology, Faculty of Medicine, Kabramanmaraş Siitçii Imam University, Kabramanmaraş, Turkey \\ ${ }^{3}$ Department of Neurosurgery, Faculty of Medicine, Kabramanmaraş Siitçii İmam University, Kabramanmaraş, Turkey \\ ${ }^{4}$ Department of Orthopaedics and Traumatology, Faculty of Medicine, Kahramanmaraş Siitçii İmam University, Kabramanmaraş, Turkey
}

\begin{abstract}
Objectives: Our aim was to investigate the morphologic and morphometric features of brachial plexus in rat and to evaluate the findings with that of the human in classical textbooks comparatively.

Methods: This study was carried out on 100 brachial plexuses of 50 adult wistar albino rats (240-280 gr) (25 males and 25 females). The overlying tissues were incised for the evaluation of brachial plexus in the axillary region. After then brachial plexus was prepared with the microdissection technique and evaluated in terms of its formation. We made the measurements related to the brachial plexus and extremities; length of upper (anterior) extremities, length and width of axillary region, brachial plexus, and roots of spinal nerves. We also noted the formation shape of brachial plexus.

Results: We found that the brachial plexus of rat was formed by C5, C6, C7, C8 and Th1 spinal nerves. Sometimes, fibers from C4 might connect with C5. The formation of brachial plexus at root level varied from each other in rats. On the other hand, some roots were thick while some of them were thin in shape. Of the contributing spinal nerves to the brachial plexus (C5-8, Th1), mean width was between 0.7-1.1 mm, mean length of merging to the trunk was 2.2-4.06 mm, while mean width of brachial plexus was $7.8 \mathrm{~mm}$, mean length was detected as $9.5 \mathrm{~mm}$. There was significant correlation with respect to $p<0.05$ and $p<0.01$ between the length and width values of the upper extremity and the values of the brachial plexus itself as well as the spinal nerves forming the plexus. In the histologic examination, mean axonal count was between 40004500 in each $\mathrm{mm}^{2}$ at the level of spinal nerve roots. The diameter and the number of axons were inversely proportional to each other.
\end{abstract}

Conclusion: Comparative knowledge on the morphometric and morphologic features of brachial plexus in rat and human can help the investigators to achieve successful results in experimental surgery.

Key words: brachial plexus; morphometry; morphology; rat; human

Anatomy 2009; 3: 21-28, (C) 2009 TSACA

\section{Introduction}

Spinal nerves of the rat consist of 34 pairs with a distribution of 8 cervical, 13 thoracic, 6 lumbar, 4 sacral and 3 caudal segments. The posterior (dorsal) branches of the spinal nerves demonstrate segmental distribution without forming plexuses. The ventral primary branches of those nerves initially merge with each other, then sep- arate and later converge and diverge again in the cervical, brachial and lumbosacral regions to form the cervical, brachial and lumbosacral plexuses. The brachial plexus in rat is formed by the contribution of ventral primary branches of the distal four cervical $(\mathrm{C} 5, \mathrm{C} 6, \mathrm{C} 7$, C8) and first thoracic spinal nerves. ${ }^{1-4}$ Contribution of nerve fibers from $\mathrm{C} 4$ may be seen both in humans and 
rats, however fibers from Th2 may contribute to the brachial plexus in humans but not in rats. ${ }^{1,2,5,6}$

Understanding and grasping the anatomy and variations of the brachial plexus lessens the rate of injury to the nerves during surgical interventions of the neck, shoulder and axillary region. The brachial plexus may frequently be under risk during the excision of neck tumors and primary tumors of the brachial plexus. ${ }^{5,7}$ New surgical methods, approaches and techniques may be conducted in rats experimentally so that the success rate of this kind of operations can be increased. Therefore, morphologic and morphometric features of the brachial plexus in rat should be known in detail. ${ }^{3,5,9,10}$

It is reported that the brachial plexus and its terminal branches provide a good experimental model which can be used to assess the development and normal control of muscle function, examine the mechanisms underlying functional recovery, and test the effects of treatments to enhance recovery. ${ }^{3,10}$

The anatomic location and structure of brachial plexus should be grasped by the surgeons dealing with its surgery due to its complex structure, relation to the neighboring structures and anatomic features of the region it is located as well as taking into consideration that the brachial plexus may exhibit frequent variations. ${ }^{5,711,12}$

At the beginning of the development, while myotom elongations taking place, they take the nerve fibers together with them originating from the same segment. Peripheral nerve fibers supplying various muscles from the same segment form nerve plexuses by converging and diverging in accordance with segmentation. ${ }^{5,7,13,14}$

The application of plexus brachialis anaesthesia is a well-known method for many surgical and orthopaedic interventions of shoulder and arm region.

To achieve successful results in these applications, however, the anatomy of the region should be grasped extensively. Otherwise, some cumbersome complications such as pneumothorax, injury to the recurrent laryngeal and phrenic nerves, and bleeding may occur. ${ }^{5-7,14}$

Our study is unique compared to the previous studies on rats investigating the formation, variations, morpho- logic features and relations of those features with the upper extremity, and also making contribution to the accumulation of information on this area. Thus lack of sufficient information on this topic led us to conduct this study. Our aim was to investigate the morphologic features of brachial plexus in rat and evaluate the findings with that of the human in classical textbooks comparatively.

\section{Materials and Methods}

This study was carried out on 100 brachial plexuses of 50 adult wistar albino rats each weighing 240-280 gram (25 males, 25 females). Those rats were not sacrificed specifically for this study. On the contrary, the rats utilized and sacrificed during other studies in our experimental animal research laboratory which were accepted suitable and assigned by the Ethics Committee for Experimental Animal Researches of our institution were used in this anatomical study.

The overlying tissues were incised for the evaluation of brachial plexus in the axillary region. After then brachial plexus was prepared with the microdissection technique and evaluated in terms of its formation.

The dissections and measurements were performed under a microsurgical microscope (SHIN-NIPPON, OP-2 U/N S824AO15) with a magnification of 5XScope (1.6 ve 2.5) and the photographs were taken with Canon EOS 500 camera.

We made the measurements related to the brachial plexus and extremities; upper (anterior) extremity length (UEL- between the shoulder process and the longest distal phalanx), axillary width (AW- the widest measurement in the axilla), plexus brachialis length (PBL- the distance from the point where the nerves merge into the truncus to the point where they separated to their peripheral branches), plexus brachialis origin width (PBOW- the distance at the origination of the plexus), plexus brachialis axillary width (PBAW- the distance at the midportion of the plexus in the axilla), cervical spinal nerve width (C5-8W), the first thoracic spinal nerve width (Th1W), cervical spinal nerve length (C5-8L- the length until merging to the plexus), the first thoracic spinal nerve length (Th1L), truncus superior, medius, 
inferior width (TSW, TMW, TIW), truncus superior, medius, inferior length (TSL, TML, TIL).

Regular anatomic compass accurate to $0.05 \mathrm{~mm}$ was used in macroscopic measurements and ocular micrometer was used in microscopic counts.

In addition to the gross anatomical investigation, we evaluated histologically the fibers of spinal nerves under the light microscope as well. Nerve tissue samples were obtained from the radicular levels for microscopic examination, routine histologic follow up was done and the samples were embedded to paraffin blocks and sections of 4-6 micron thickness were obtained and stained with hematoxylin-eosin. After then, required measurements were done and a sample picture of C8 section was taken.

Statistical analyses were performed by SPSS 13.0 package software by the utilization of Pearson Correlation and Spearman's rho tests (correlation is significant at the 0.05 and 0.01 level).

\section{Results}

We found that the brachial plexus of rat was formed by C5, C6, C7, C8 and Th1 spinal nerves. In most rats, fibers from C4 might connect with C5 (66\%). However,

Figure 1. The general appearance of left plexus brachialis in rat. $C(5-8)$ : cervical spinal nerves; T1: first thoracic spinal nerve, Th1; TS: truncus superior; TM: truncus medius; TI: truncus inferior; FL: fasciculus lateralis; FM: fasciculus medialis; FP: fasciculus posterifor; contributing branch from C4 (small black arrows); NS: nervus suprascapularis.

Figure 2. A variation of absence of truncus inferior of right plexus brachialis at root and truncus level in rat. $C(5-8)$ : cervical spinal nerves; T1: first thoracic spinal nerve, Th1; TS: truncus superior, TM: truncus medius.
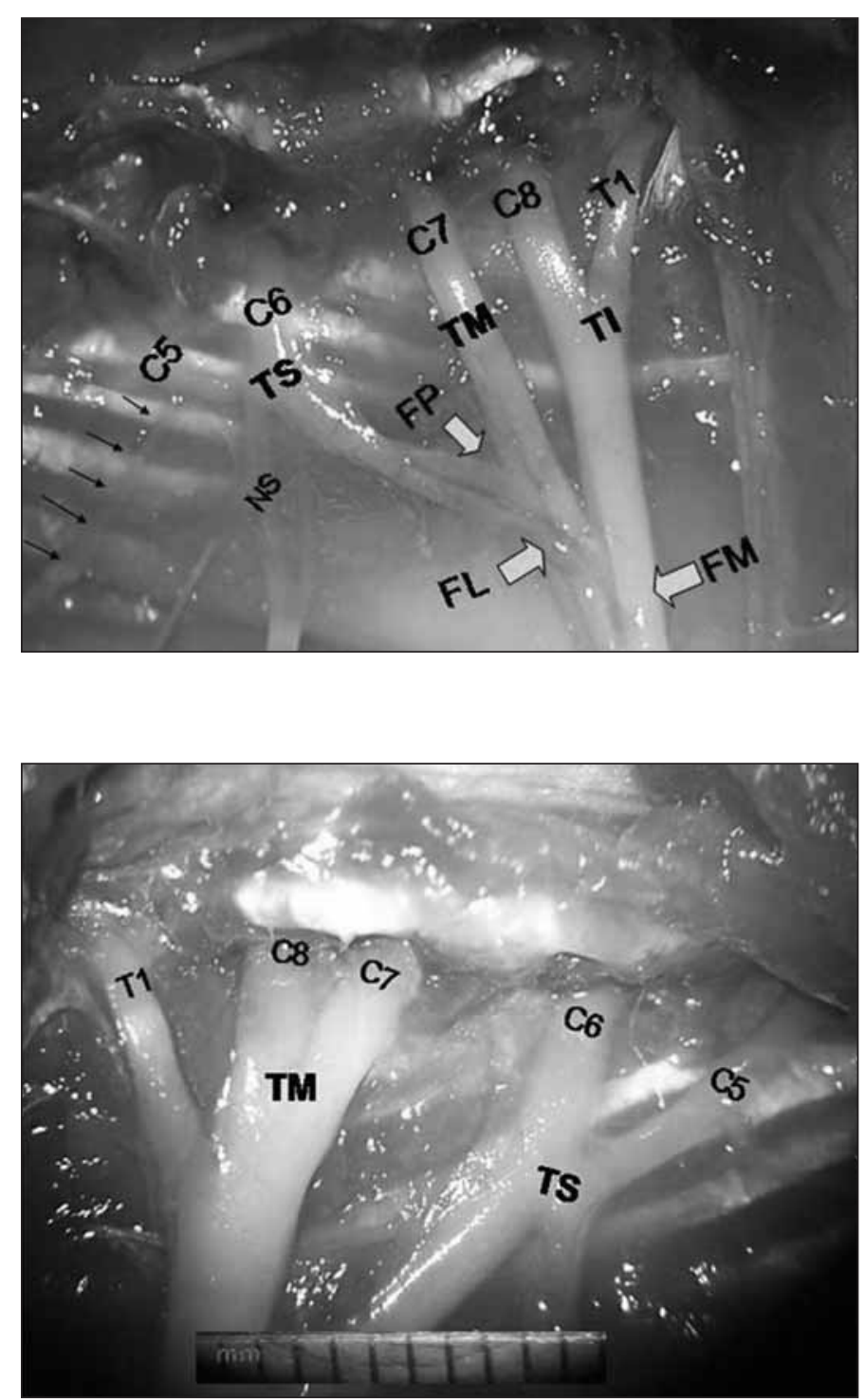

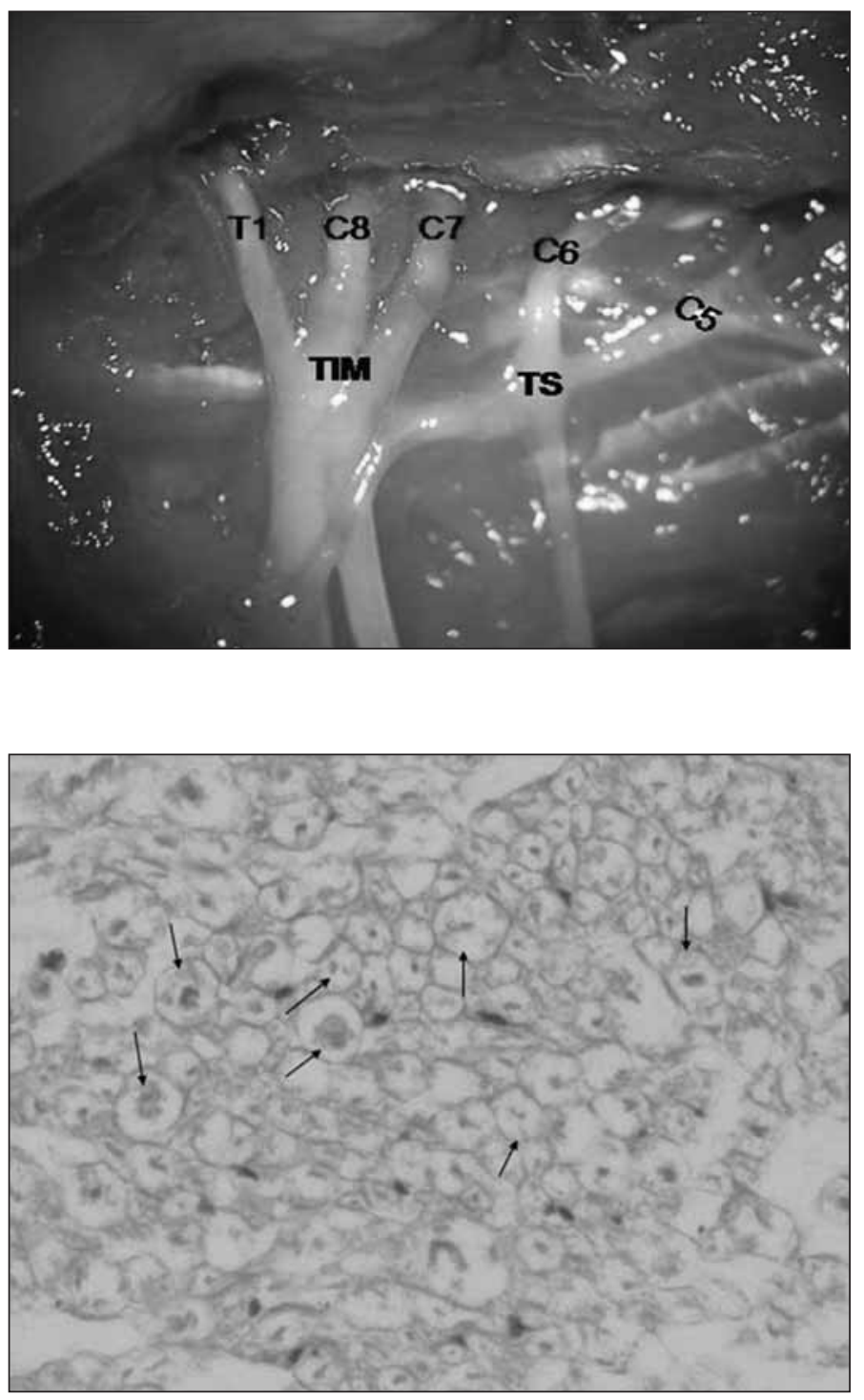

Figure 3. A variation of truncus inferio-medialis of right plexus brachialis in rat. $C(5-8)$ : cervical spinal nerves, $\mathrm{T} 1$ : first thoracic spinal nerve, Th1; TS: truncus superior; TIM: truncus inferio-medialis.

Figure 4. The appearance of transversal section of ventral root of eigth cervical spinal nerve (C8) in rat. Arrows: axons (H\&E X40). any contribution from Th2 to Th1 was not detected. While C7 and C8 combined and formed truncus medius (TM) in some cases (27\%), a common trunk (truncus inferio-medialis) was formed in some others by the combination of C7, C8 and Th1 (7\%) (Figures 1-3). Approximately similar rates were found in right and left extremities of both male and female rats. The average values and standard deviations of our measurements were given in Table $\mathbf{1 .}$

The formation of brachial plexus at root level varied from each other in rats. On the other hand, some roots were thick while some of them were thin in shape.
Of the spinal nerves contributed to the brachial plexus (C5-8, Th1), average width was between 0.7-1.1 $\mathrm{mm}$, average length until merging to the plexus was between 2.2-4.06 $\mathrm{mm}$, average width of the plexus was $7.8 \mathrm{~mm}$, and average length of the plexus was $9.5 \mathrm{~mm}$ (Table 1).

Statistically significant correlation was found between the values of upper (anterior) extremity and brachial plexus as well as the values of the spinal nerves forming the plexus. That is, significant correlation $(\mathrm{p}<0.05)$ was found between the length of upper (anterior) extremity and both axillary width and the width of spinal nerve roots. $(\mathrm{p}<0.05)$ (Table 2$)$. 
Table 1

The mean values of plexus brachialis in rat

\begin{tabular}{lll}
\hline Measurements & Mean $(\mathbf{m m})$ & \pm SD \\
\hline UEL & 102.9 & 4.1 \\
AW & 31.4 & 2.01 \\
PBL & 9.5 & 1.2 \\
PBOW & 12.8 & 1.3 \\
PBAW & 7.8 & 0.7 \\
C5W & 0.7 & 0.06 \\
C6W & 0.9 & 0.04 \\
C7W & 1.08 & 0.1 \\
C8W & 1.1 & 0.1 \\
Th1W & 0.8 & 0.1 \\
C5L & 4.06 & 0.4 \\
C6L & 2.4 & 0.3 \\
C7L & 3.4 & 2.5 \\
C8L & 2.2 & 0.7 \\
Th1L & 3.02 & 0.5 \\
TSW & 1.6 & 0.2 \\
TMW & 1.1 & 0.1 \\
TIW & 1.6 & 0.2 \\
TSL & 1.9 & 0.3 \\
TML & 4.5 & 3.3 \\
TIL & 3.1 & 1.2 \\
\hline
\end{tabular}

On the other hand, significant correlation $(\mathrm{p}<0.05)$ was found between the axillary width, the width of spinal nerve roots and the length of Th1 (Table 2).

Furthermore, there was also significant correlation between the axillary width of the brachial plexus, with

Table 2

The correlation values between measurements of plexus brachialis in rat

\begin{tabular}{lll}
\hline Measurements & \multicolumn{2}{c}{ Correlation values } \\
\hline mm & P<0.05 & P<0.01 \\
\hline UEL & AW, Th1W & C5W, C6W, C7W, C8W \\
AW & Th1L & - \\
PBL & - & C6W \\
PBOW & - & PBAW, TSL \\
PBAW & Th1W & C6W, C7W, C8W, \\
C5W & Th1W & C6W, C7W, C8W, Th1W \\
C6W & C5L, C6L, Th1L, TSL & C7W, C8W, Th1W, TIW \\
C7W & Th1L & C8W, Th1W,TIW \\
C8W & Th1L & Th1W, TIW \\
Th1W & Th1L,TIW & - \\
C5L & - & C6L \\
C6L & - & TSL \\
C7L & - & C8L, TML \\
\hline
\end{tabular}

the width of the brachial plexus at its origin $(\mathrm{p}<0.05)$ and the width of spinal nerve roots $(\mathrm{p}<0.01)$ (Table 2$)$.

Significant correlation was found between the width of C6, with the length $(\mathrm{p}<0.05)$ and the width $(\mathrm{p}<0.01)$ of spinal nerves (Table 2).

The length of each cervical spinal nerve till merging to the plexus was examined and significant correlation was found between each length and the length of other cervical spinal nerves as well as the length of superior and medial trunci (Table 2).

When right and left extremity values were examined according to the gender, then the findings and statistical values were submitted as to $\mathrm{p}<0.05$ and $\mathrm{p}<0.01$ (Table 3 ).

In addition to the gross anatomical investigation, we evaluated histologically with the aid of oculary micrometer the fibers of spinal nerves under the light microscope as well. The average number of axons per $\mathrm{mm}^{2}$ was counted as between 4000-4500 in the transversal sections of spinal nerve roots (Figure 4). Number of axons in the spinal nerve root was changing in relation with the axonal diameter. Number of axons in the spinal nerve root was more when the axonal diameter is less and vice versa.

\section{Discussion}

This study was planned especially with the assumption that it would make substantial contribution to the experimental investigators on the brachial plexus of rats. The information on morphometric and morphologic features of the brachial plexus will play the most remarkable role.

The brachial plexus in rat was reported in many studies to be formed by the contribution of ventral primary branches of C5, C6, C7, C8 and Th1 spinal nerves with some fibers from $\mathrm{C} 4$ in $60-65 \%$ of cases but never received any fibers from Th2. .,2,, $14^{-14}$

On the other hand, the brachial plexus in humans was reported to be formed by the fibers of ventral branches of C5-C8 and Th1 spinal nerves similar to that of rats. Contribution of fibers from $\mathrm{C} 4$ in humans was seen in $65 \%$, Th2 in $30 \%$ of cases, however co-existence of fibers from both segments was reported in $5-8 \%$ of sub- 
jects. The existence of fibers from C4 in the plexus was called prefix and from Th2 was called postfix. ${ }^{5-7}$

In our study, the brachial plexus in rats was observed to be formed by the contribution of ventral branches of C5, C6, C7, C8 and Th1 spinal nerves.
Contribution of nerve fibers from $\mathrm{C} 4$ was seen in $66 \%$, however fibers from Th2 were observed in non of the rats in this study.

Our findings on the formation of roots were in accordance with other studies both in rats and humans.

Table 3

The statistical relationship of values among measurements according to sex and extremities

\begin{tabular}{|c|c|c|c|}
\hline Extremity & Sex & $P<0.05$ & $P<0.01$ \\
\hline \multirow[t]{2}{*}{ Right } & Male $(n=25)$ & $\begin{array}{l}\text { (UEL - TML), } \\
(\mathrm{C} 8 \mathrm{~W}-\mathrm{TML}) \\
(\mathrm{Th} 1 \mathrm{~W}-\mathrm{Th} 1 \mathrm{~L})\end{array}$ & $\begin{array}{l}(\mathrm{C} 6 \mathrm{~W}-\mathrm{C} 7 \mathrm{~W}) \\
(\mathrm{C} 7 \mathrm{~W}-\mathrm{Th} 1 \mathrm{~W}) \\
(\mathrm{C} 7 \mathrm{~W}-\mathrm{Th} 1 \mathrm{~L}) \\
(\mathrm{C} 7 \mathrm{~L}-\mathrm{TML})\end{array}$ \\
\hline & Female $(n=25)$ & $\begin{array}{l}\text { (AW - PBOW, C7L, TML), } \\
\text { (PBL - Th1W), } \\
\text { (PBAW - TIW), } \\
\text { (PBOW - C6W, C8W, C8L), } \\
\text { (C5W - TIL), } \\
\text { (C5W - TML), } \\
\text { (C6W - C8L), } \\
\text { (C7W - C8W, TIW), } \\
\text { (C8W - C7L, C8L), } \\
\text { (Th1W - Th1L), } \\
\text { (C7L - TML), } \\
\text { (TIW - TML), } \\
\text { (TML - TIL) }\end{array}$ & $\begin{array}{l}\text { (UEL - Th1W, C6L, Th1L, TSL), } \\
\text { (PBOW - C7L), } \\
\text { (C5W - TML), } \\
\text { (C6W - C6L), } \\
\text { (C7W - TIL), } \\
\text { (Th1W - TSL), } \\
\text { (C7L - C8L), } \\
\text { (Th1L - TSL), } \\
\text { (TIW - TIL) }\end{array}$ \\
\hline \multirow[t]{2}{*}{ Left } & Male $(n=25)$ & 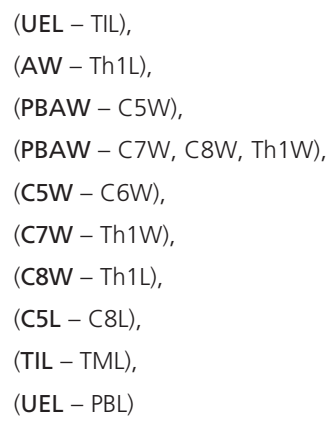 & $\begin{array}{l}(\mathrm{PBAW}-\mathrm{C} 6 \mathrm{~W}), \\
(\mathrm{C} 5 \mathrm{~W}-\mathrm{C} 7 \mathrm{~W}, \mathrm{C} 8 \mathrm{~W}), \\
(\mathrm{C} 6 \mathrm{~W}-\mathrm{C} 7 \mathrm{~W}, \mathrm{C} 8 \mathrm{~W}), \\
(\mathrm{C} 7 \mathrm{~W}-\mathrm{C} 8 \mathrm{~W}) \\
(\mathrm{C} 8 \mathrm{~W}-\mathrm{Th} 1 \mathrm{~W}) \\
(\mathrm{C} 8 \mathrm{~W}-\mathrm{Th} 1 \mathrm{~L}) \\
(\mathrm{C} 8 \mathrm{~L}-\mathrm{C} 7 \mathrm{~L}) \\
(\text { Th1 } 1 \mathrm{~L}-\mathrm{TML})\end{array}$ \\
\hline & Female $(n=25)$ & $\begin{array}{l}(\mathrm{UEL}-\mathrm{PBAW}) \\
(\mathrm{AW}-\mathrm{PBOW}) \\
(\mathrm{PBOW}-\mathrm{Th} 1 \mathrm{~W}) \\
(\mathrm{C} 5 \mathrm{~W}-\mathrm{C} 6 \mathrm{~W}, \mathrm{C} 7 \mathrm{~W}) \\
(\mathrm{C} 6 \mathrm{~W}-\mathrm{Th} 1 \mathrm{~W}, \mathrm{TSL}), \\
(\mathrm{C} 5 \mathrm{~L}-\mathrm{Th} 1 \mathrm{~L}) \\
(\mathrm{TSL}-\mathrm{PBOW})\end{array}$ & 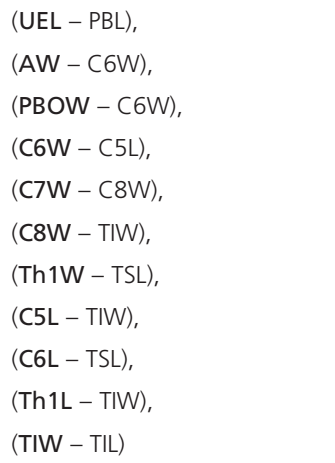 \\
\hline
\end{tabular}


The average width of roots contributing to the plexus was stated as $0.5-1.2 \mathrm{~mm}$ and of trunci was reported as $1.1-1.3 \mathrm{~mm}$ in some studies. ${ }^{1,3,9}$ However, the average width of roots contributing to the plexus was found as 0.7-1.1 $\mathrm{mm}$, average length till merging to the plexus was 2.2-4.06 $\mathrm{mm}$, average width of trunci was 1.1-1.6 $\mathrm{mm}$ and average length was $1.9-4.5 \mathrm{~mm}$ in our study.

The width values of the roots and truncus levels were parallel with the previous studies, however we were not able to discuss our findings on the length of spinal nerves till merging to the plexus since there was no data on this topic.

In many studies performed, it was stated that C5, C6 united and formed truncus superior, C7 solely formed truncus medius and $\mathrm{C} 8$, Th1 united to form truncus inferior both in humans and rats. However, there may be some variations in the formation of these trunci. It was observed that the brachial plexuses in rats and humans were similar from the aspects of formation of roots and trunci as well as the ventral-dorsal branching patterns of the trunci. ${ }^{1,5,7,9} \mathrm{We}$ mainly observed in the rats in our study that C5, C6 united and formed truncus superior, C7 formed truncus medius alone and C8, Th1 united to form truncus inferior. However, in some cases it was encountered that $\mathrm{C} 7$ and $\mathrm{C} 8$ formed truncus medius, or C7, C8 and Th1 united and formed truncus inferomedialis instead of separate medial and inferior trunci (Figures 1-3). These findings were parallel with the results of other previous studies performed on the brachial plexus of both humans and rats.

A number of new measurements were done in our study which were not performed in the previous studies (Tables 1-3). Statistically significant correlation was found between the values of upper (anterior) extremity length and axillary width on one hand and the width of brachial plexus as well as the width of spinal nerves forming the plexus and the length of these nerves till merging to the plexus on the other.

In the literature search, no similar study could be found dealing with the morphometric measurements of the upper (anterior) extremity and brachial plexus of rats. Therefore, comparison or discussion on the morphome- tric measurements of the spinal nerves forming the brachial plexus of rats could not be done. Hence, we think that our study can be a reference guide to the later studies from that aspect.

It was thought that the formation, position, and distribution variations in the brachial plexus encountered generally among the species were associated with muscle and nerve relation in providing muscle-motion coordination convenient to the goal, especially muscle-nerve distribution in the motor innervation of the muscles directed to the shoulder, chest and flexion movement, and likely changes in this distribution. Starting from this point, it was stated that the most developed and functionally complicated brachial plexus model in providing muscle-motion coordination convenient to the goal was in man..$^{5-7}$ Hence, regional anesthesia was reported to be more superior to general anesthesia and provide good analgesia in special surgical interventions on the upper extremity.

Therefore, the better the anatomy of this region is known, the more confidently and effectively the regional anesthesia will be performed. Various studies are being conducted on rat models in order the microsurgical techniques performed in brachial plexus lesions to be more successful and to develop novel techniques. Formation of the brachial plexus and distribution of its peripheral branches in rat and human were reported to be more similar compared to many other experimental animals. ${ }^{1,3,5,9}$

The similarity in organization of the brachial plexuses in rat and human makes it possible to prefer the rats especially in experimental surgery and microsurgery studies. Therefore, this kind of morphologic and morphometric studies on rats are intensely required. Our study may contribute to the substantiation of demand on this area.

There is a widespread assumption that the number of fascicles and axons are essential in repairing the peripheral nerve lesions. Preference of similar nerve segments with similar number of axons and fascicles in accordance with the damaged one in experimental applications is vital in regaining the related functions. . $^{1,-5,9,10}$ 
The average number of axons per $\mathrm{mm}^{2}$ was counted as between 4000-4500 in the transversal sections of spinal nerves at the level of roots in our study. Number of axons was less in the nerves with greater axonal diameter and number of axons was more in nerves with smaller axonal diameter in our observations. Unfortunately we were not able to access any study on the axonal count in the spinal nerves at the root level of rats. We believe that our results may be beneficial and important for the investigators especially dealing with the repair of peripheral nerves and experimental surgery.

Comparative knowledge on the morphometric features of brachial plexus in rat and human can help the investigators to achieve more successful results in experimental surgery.

\section{References}

1. Uzun A, Cengiz N, Kavaklı A, Karakas S. Morphological and microscopical examination of the rat brachial plexus. Turk $\mathcal{f}$ Vet Anim Sci 2001; 25: 397-402.

2. Popesko P, Rajtova V, Horak J. A Colour Atlas of Anatomy of Small Laboratory Animals. Vol. 2: Rat, Mouse, Hamster. London: Saunders, Elsevier Science Ltd.; 2002.

3. Bertelli, JA, Mira JC. Behavioral evaluating methods in the objective clinical assessment of motor function after experimental brachial plexus reconstruction in the rat. 7 Neurosci Methods 1993; 46: 203-8.
4. Bertelli JA, Mira JC. The grasping test a simple behavioral method for objective quantitative assesment of peripheral nerve regeneration in the rat. 7 Neurosci Methods 1995; 58: 151-5.

5. Büyükkiraz M. Plexus brachialis yapısı, varyasyonları ve cerrahi önemi (Uzmanlık Tezi). Istanbul: 2005.

6. Lee HY, Chung H, Seok W, Kang HS, Lee HS, Ko, JS, Lee MS. Park SS. Variations of the ventral rami of the brachial plexus. 7 Korean Med Sci 1992; 7: 19-24.

7. Sarsılmaz M, Şendemir E, Çelik H, Gümüşalan Y, Şimşek C. Some variations of the brachial plexus in man. Turkish fournal of Medical Research (Ankara) 1993; 2: 161-5.

8. Karabiber H, Özkan KU, Garipardic M, Parmaksız G. An overlooked association of brachial plexus palsy: diaphragmatic paralysis. Acta Paediatr Taiwan 2004; 45: 301-3.

9. Bertelli JA, Mira JC, Gilbert A, Michot GA. Anatomical basis of rat brachial plexus reconstruction. Surg Radiol Anat 1992; 14: 84-6.

10. Berteli JA, Taleb M, Saads A, Mira JC, Pecot DM. The rat plexus brachialis and its terminal branches, on experimental model for the study of peripheral nerve regeration. Microsurgery 1995; 16: 77-85.

11. Sargon MF, Borman H. An anomalous formation of the median nerve. Gazi Medical fournal (Ankara) 1984; 51-3.

12. Sargon M, Uslu SS, Çelik HH, Akşid D. A variation of the median nerve at the level of brachial plexus in man. Bullettin de l'Association des Anatomistes 1995; 79: 25-6.

13. Moore KL. (Transl. eds.: Yıldırım M, Okar I, Dalçık H). İnsan Embriyolojisi. İstanbul: Nobel Tip Kitabevi; 2002.

14. Haines, DE. Fundamental Neuroscience. New York; Churchill Livingstone; 1997 p. 2-3, 70-4.

Correspondence to: Davut Özbağ, PhD Department of Anatomy, Faculty of Medicine, Kahramanmaras Sutcu Imam University Kahramanmaras 46050 Turkey e-mail: dozbag@ksu.edu.tr Conflict of interest statement: No conflicts declared. 